\author{
ISSN: 2757-6485
}

$2021 \& 2(3)$

\author{
Investigation of Ratios and Distances in Triple Jump Hop-Step-Jump \\ Phases \\ Sibel TETIK DÜNDAR ${ }^{1}$
}

\section{ORGINAL ARTCILE}

\section{History}

Received: 15 November 2021

Accepted: 6 December 2021

Published: 30 December 2021

DOI:http://dx.doi.org/10.29228/anatoliasr.17

Authors Communications

1- (Cotrresponded Author)

Erzincan Binali Yildırım University, Faculty of

Spor Sciences, Erzincan, Turkey

stetik@erzincan.edu.tr

https://orcid.org/0000-0001-6813-0969

\section{Acknowledgement}

All authors contributed to the conception and design of the study.

\section{Funding}

This study received no specific financial support.

\section{Competing Interests}

The authors declare that they have no conflict of interests.

\section{Transparency}

The authors confirm that the manuscript is an honest, accurate, and transparent account of the study was reported; that no vital features of the study have been omitted; and that any discrepancies from the study as planned have been explained.

\section{Ethical}

This study follows all ethical practices during writing.

\section{Citation}

Tetik Dündar, S. (2021). Investigation of Ratios and Distances in Triple Jump Hop-Step-Jump Phases, Anatolia Sport Research, 2(3):10-17.

Copyright (C) 2021 by Anatolia Sport Research

\begin{abstract}
Aim: This study was carried out to determine the dominant techniques used by the jumpers on the basis of rate and distance in the triple jump hop-step-jump phases and to examine the biomechanical analysis of the complex motion cycle in the triple jump with the inverse dynamic simulation method.

Material and Method: The analyses made considering the 2009 and 2011 World Championships in Athletics and the women's and men's triple jump finals, the 1992 USA Athletics Olympic Team Trials men's triple jump final, and the Egyptian national trial official results were examined. The distance traveled by all the jumpers in the flight phases $(\mathrm{m})$ and the phase ratios $(\%)$ that occur with it are listed. The study was conducted with the microanalysis method based on literature research. Results: In the 2009 World Athletics Championships triple jump final results, the same technique (hop dominant) was used dominantly for both women and men, and the same technique (balance dominant) was used dominantly for both women and men in the 2011 World Athletics Championships triple jump final results, 1992 USA Athletics Olympics It was seen that balance dominant technique was used in Team Trials triple jump men's final results.

Conclussions: According to the results of the competition examined, it was seen that the quantitative success was higher in the phases in which the balance dominant technique was used in men, while close results were obtained in both hop dominant and balance dominant techniques in women. In the important national and international competitions, it has been observed that while the jumpers used the jump dominant technique widely before, this situation has been replaced by more balance and hop dominant techniques recently.
\end{abstract}

Keywords: İnverse Dynamics Simulation, Phase Ratios, Triple Jump. 


\section{INTRODUCTION}

Triple jump is one of the technical branches of athletics, which is considered difficult and has a complex structure, includes short-term and explosive muscle power, and where different movements come together (aperiodic) in succession. Followed by the approach run on the runway, the triple jump consists of a hop, a stepping (kangaroo step), and jump into the sandbox,

Stage 1 (approach run); is characterized by the mass displacement of the athlete at the highest speed (in the $35 \mathrm{~m}-45 \mathrm{~m}$ area) up to the stepping board, where he will start the three-step stage.

Stage 2 (hop/bounce); ends with the athlete hopping by touching the footboard with one foot, carrying the same foot forward with the movement of a bicycle in the air, and falling/stepping on the same foot again. Meanwhile, the athlete carries the other leg forward in a close cycle of motion. The hop step can generally be expressed as a large form leap step.

Stage 3 (step taking); The step-taking phase, which can be expressed with the kangaroo step, can be compared to the open compass shape with the foot bent, which the athlete makes by swinging his dominant leg back in the 2nd stage, with the other leg forward, up to the hip level, with the leg bent at the knee, lifting it up and forward. It is the most forward carrying of the body mass by taking the foot off the ground and taking a step.

Stage 4 (jump/flight); is characterized by the fact that the athlete carries the body mass to the sandbox at the highest level with the action effect of the 3rd stage. At this stage, the athlete carries both legs to the parallel position during the jump, reaches the position of sitting in the air, or tries to carry him/herself most forward by walking in the air with the scissoring technique. The fall phase ends in a standing or hip (lateral) position.

Triple jump is a branch in which it is necessary to repeat the maximum force generation in order to maintain horizontal speed in all phases of the jump (Miladinov and Bonov, 2004). The jumper's ability to basically build well during each of the 3 take-off stages is crucial (Yu, 1999). In each take-off phase, changes occur in the structure and rhythm of the movement, which affects the timing of the eccentric contraction (Koh and Hay, 1990). Each phase has its own dynamics during braking and propulsion. For this reason, the direction and magnitude of the force and the duration of action play a very important role in this branch (Hay, 1999).

The contact between the foot and the ground causes a decrease in the vertical and horizontal speed of the jumper. Horizontal speed is gained during the approach run, and contact with the ground during each of the take-off stages causes this speed to decrease. Using the correct and effective take-off technique at the relevant stages can reduce speed losses. One of the most important reasons for the difference between the performances of the jumpers in the triple jump is the difference in horizontal speed losses. This situation is a result of the physical and technical characteristics of the jumpers (Eissa, 2014).

For this, performing mechanical-dynamic-kinematic analysis, quantitative evaluation of gains and losses in horizontal speed, giving technical corrective warnings in jumpers can lead to quantitative improvements in competition records. 


\section{Reverse Dynamics Simulation}

During jumping, due to the strong impact forces between the foot and the ground, the muscletendon effort, which is more reflected on the internal loads of the lower extremity joints, can quickly lead to the risk of injury. For this reason, the triple jump branch is seen as one of the most challenging athletic activities in terms of technical and physical abilities (Hay, 1992; Perttunen et al., 2000; Čoh et al., 2015).

It is important for the athlete specializing in this branch to have a distinctively special strength structure in terms of versatile development, coordination, agility, and speed parameters, especially the muscle-tendon-joint structure in the lower extremities and hips.

Qualitative and quantitative analyzes and biomechanical evaluations to be made in the triple jump can be the tactical key to success for this branch, as a result of taking into account the techniques specific to the branch, and making all the phases to be performed separately and specific to the athlete.

This branch, which consists entirely of technical movements from the start of the jump to the finish, includes fully active body mass activity, including arms, feet, trunk, head position.

In this regard, there are studies on the reverse dynamic simulation of the triple jump, which aims to quantitatively evaluate external and internal loads during movement. In order to understand the triple jump technique and the mechanisms that can cause injury; it has been stated that predicting the internal loads on the lower extremity joints and the muscular force interaction that creates the movement constitutes an important infrastructure (Čoh et al., 2015).

Reverse dynamics analysis, based on musculoskeletal modeling and non-invasive kinematic recordings, is extensively used in the study of human movement biomechanics and motor control. However, applications on triple jump analysis are rare (Erdemir et al., 2007; Robertson et al., 2004; Seireg and Arvikar, 1989; Winter, 2005).

Modeling in the reverse dynamic analysis is quite difficult as the detection of human movements becomes complicated by devices. Therefore, there are often simplified situations and errors in modeling. However, it is the only non-invasive method available for the assessment of internal loads in human movements. In addition, advanced analyzes were made on examining the relationship between some parameters in the models and muscle strength and expressing the sensitivity in quantitative ways (Blajer et al., 2010; Garner and Pandy, 2000; Zajac and Winters, 1990).

In the analysis results, it was stated that the external reactions originating from the ground are moderate in triple jumps, the internal loads on the lower limbs can be very severe, and this situation shows itself in injuries and long-term exercises (Allen, 2009; Hay, 1992; Perttunen et al., 2000).

It is very important to know the muscle strength and joint reactions of the athletes in order to correctly evaluate the possible risks during the triple jump. This information is essential in calculating internal and external loads and improving inverse dynamic simulations, accurately recording the effects at the points where the foot contacts the ground with severe pressure and increasing the shooting frequency $(100 \mathrm{~Hz})$ (Čoh et al., 2015). 


\section{Ratio and Distance Analysis in Phases}

In the triple jump, the distances covered in the three flight phases are evaluated separately and the resulting ratios are determined by which technique the athlete is physically inclined to the branch. The ratio of the percentages in these three flight phases is known as the phase ratio and is used as a measure of effort distribution (Hay, 1992).

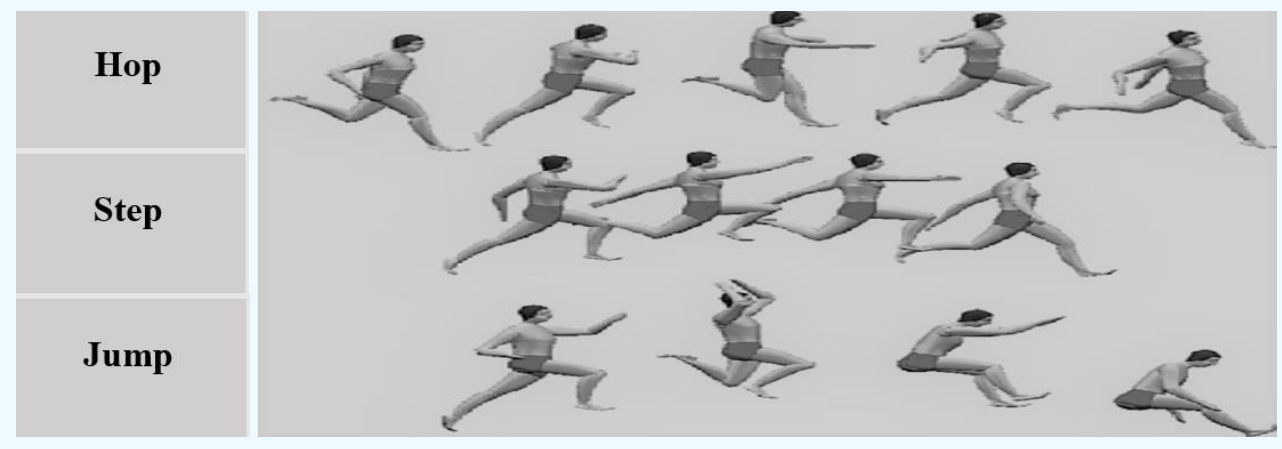

Figure 1. Computer Simulation Image of Hop-Step-Jump Phases in Triple Jump

Techniques are examined in three ways according to the phase ratio;

a) It is the technique in which the ratio in the hop phase is higher (at least $2 \%$ ) than the ratio in the jump phase. This technique is also known as the vertical hop and jump technique (Middle East). It is a technique preferred by jumpers with high hop force and low speed.

b) It is the technique in which the ratio in the jump phase is higher (at least $2 \%$ ) than the ratio in the hop phase. This technique is also known as the low hop and jump technique (De Silva). It is a technique preferred by jumpers with high speed and slightly low hop force.

c) It is a technique in which the difference between the ratios in the hop and jump phases is less than $2 \%$ and the balance is preserved in the ratios (Hay, 1992).

Some studies have mentioned that there are individualized optimum phase ratios at each stage of triple jump due to the individualized relationships between loss in horizontal speed and gain in vertical speed (Yu, 1999; Yu and Hay, 1996; Liu and Yu, 2012). For an athlete, the linear relationship indicator between the loss in horizontal speed and the gain in vertical speed is called the speed conversion coefficient and this coefficient determines the ratio in the best phase (Liu and $\mathrm{Yu}, 2012$ ).

Although a limited number of phase ratio and distance analyzes have been made in world athletics, national and international scales have been accessed and presented in tables. It has been observed that the number of studies carried out in this area is quite low. For this reason, it is thought that general inferences can be drawn from the sample results obtained from different nations, even though clear decisions cannot be reached on the population.

\section{RESULTS}

Table 1. Phase Analysis in Egyptian National Athlete Enas Gharieb' Trials (Eissa, 2014).

\begin{tabular}{lcccc}
\hline Deneme & $\mathbf{1}$ & $\mathbf{2}$ & $\mathbf{3}$ & $\mathbf{4}$ \\
\hline Hop $(\mathbf{m})$ & 4.05 & 4.23 & 3.88 & 4.50 \\
\hline Step $(\mathbf{m})$ & 3.67 & 3.64 & 3.65 & 3.78 \\
\hline Jump (m) & 4.48 & 4.53 & 5.02 & 4.72 \\
\hline
\end{tabular}




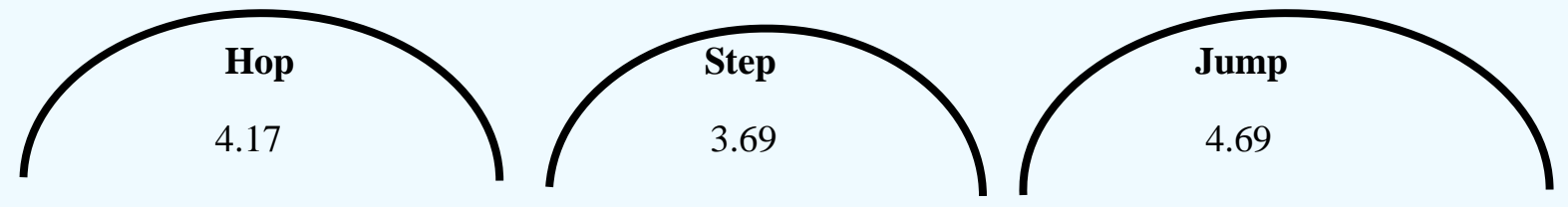

Figure 2. Average Values in Phase Distances of Enas Gharieb

When Table (1) and figure (1) are examined, it is seen that the jumper used the De Silva (jump dominant) technique, which is known as the low hop and jump technique, dominantly in the trials.

Table 2. Berlin 2009 IAAF World Championships in Athletics Men's Triple Jump Phase Rates and Distances Analysis (Hommel, 2009; Bayraktar and Çilli, 2017).

\begin{tabular}{lcccccc}
\hline & Hop $(\mathbf{m})$ & Step (m) & Jump (m) & Hop (\%) & Step (\%) & Jump (\%) \\
\hline Idowu P. & 6.49 & 5.41 & 6.02 & 36 & 30 & 34 \\
\hline Evora N. & 6.51 & 5.41 & 5.68 & 37 & 31 & 32 \\
\hline Copello A. & 6.01 & 5.77 & 5.92 & 34 & 33 & 33 \\
\hline Sands L. & 6.52 & 5.20 & 5.62 & 38 & 30 & 32 \\
\hline Girat A. & 6.16 & 5.41 & 5.88 & 35 & 31 & 34 \\
\hline Li Y. & 6.33 & 5.24 & 5.75 & 37 & 30 & 33 \\
\hline Spasovkhodskiy I. & 6.47 & 4.80 & 5.69 & 38 & 28 & 34 \\
\hline Gregorio J. & 6.33 & 5.10 & 5.72 & 37 & 30 & 33 \\
\hline Mean & 6.35 & 5.29 & 5.79 & 37 & 30 & 33 \\
\hline
\end{tabular}

When Table 2 is examined, it is seen that male jumpers use the Middle East, that is, the vertical hop and jump technique (hop dominant) dominantly in the average phase ratios and distances.

Table 3. Berlin 2009 IAAF World Athletics Championships Women's Triple Jump Final Phase Rates and Distances Analysis (Hommel, 2009; Bayraktar and Çilli, 2017).

\begin{tabular}{lcccccc}
\hline & Hop $(\mathbf{m})$ & Step $(\mathbf{m})$ & Jump $(\mathbf{m})$ & Hop (\%) & Step (\%) & Jump (\%) \\
\hline Savigne Y. & 6.49 & 5.41 & 6.02 & 36 & 30 & 34 \\
\hline Gay M. & 6.51 & 5.41 & 5.68 & 37 & 31 & 32 \\
\hline Pyatykh A. & 6.01 & 5.77 & 5.92 & 34 & 33 & 33 \\
\hline Topic B. & 6.52 & 5.20 & 5.62 & 38 & 30 & 32 \\
\hline Smith T. & 6.16 & 5.41 & 5.88 & 35 & 31 & 34 \\
\hline Lebedeva T. & 6.33 & 5.24 & 5.75 & 37 & 30 & 33 \\
\hline Bujin C. & 6.47 & 4.80 & 5.69 & 38 & 28 & 34 \\
\hline Veldakova D. & 6.33 & 5.10 & 5.72 & 37 & 30 & 33 \\
\hline Mean & 5.38 & 4.20 & 5.04 & 37 & 29 & 34 \\
\hline
\end{tabular}

When Table 3 is examined, it is seen that the Middle East technique is used dominantly in the average phase ratios and distances in female athletes as well as in male jumpers.

Table 4. Daegu 2011 IAAF World Championships in Athletics Men's Three Jump Men Final Phase Rates and Distances Analysis (Woo and Kim, 2011; Bayraktar and Çilli, 2017).

\begin{tabular}{lcccccc}
\hline & Hop $(\mathbf{m})$ & Step $(\mathbf{m})$ & Jump $(\mathbf{m})$ & Hop (\%) & Step (\%) & Jump (\%) \\
\hline Taylor C. & 6.19 & 5.29 & 6.62 & 34 & 29 & 37 \\
\hline Idowu P. & 6.67 & 5.64 & 5.60 & 37 & 32 & 31 \\
\hline Claye W. & 5.77 & 5.43 & 6.47 & 33 & 31 & 36 \\
\hline Copello A. & 6.40 & 5.38 & 5.84 & 36 & 31 & 33 \\
\hline
\end{tabular}




\begin{tabular}{lllllll}
\hline Evora N. & 6.44 & 5.18 & 5.84 & 37 & 30 & 33 \\
\hline Olsson C. & 6.37 & 5.09 & 5.99 & 37 & 29 & 34 \\
\hline Sandsa L. & 6.63 & 4.77 & 6.19 & 38 & 27 & 35 \\
\hline Compaore B. & 6.32 & 5.23 & 5.93 & 36 & 30 & 34 \\
\hline Mean & 6.35 & 5.25 & 6.06 & 36 & 30 & 34 \\
\hline
\end{tabular}

When Table 4 is examined, considering the phase ratios and distances, it is seen that male jumpers generally maintain their hop-jump balance, that is, they use the balance dominant technique.

Table 5. Daegu 2011 IAAF World Athletics Championships Women's Triple Jump Final Phase Rates and Distances Analysis (Woo and Kim, 2011; Bayraktar and Çilli, 2017).

\begin{tabular}{lcccccc}
\hline & Hop $(\mathbf{m})$ & Step $(\mathbf{m})$ & Jump (m) & Hop (\%) & Step (\%) & Jump (\%) \\
\hline Saladuha O. & 5.73 & 4.15 & 5.16 & 38 & 28 & 34 \\
\hline Rypkova O. & 5.38 & 4.23 & 5.53 & 35 & 28 & 37 \\
\hline Ibarguen C. & 5.48 & 4.19 & 5.22 & 37 & 28 & 35 \\
\hline Gay M. & 5.55 & 4.33 & 5.04 & 37 & 29 & 34 \\
\hline Aldama Y. & 5.62 & 4.49 & 4.51 & 38 & 31 & 31 \\
\hline Savigne Y. & 5.18 & 3.82 & 5.59 & 36 & 26 & 38 \\
\hline Kuropatkina A. & 5.03 & 4.18 & 5.02 & 35 & 30 & 35 \\
\hline Rahouli B. & 4.95 & 4.23 & 5.08 & 35 & 30 & 35 \\
\hline Mean & 5.37 & 4.20 & 5.14 & 36 & 29 & 35 \\
\hline
\end{tabular}

When Table 5 is examined, when phase ratios and distances are taken into account, it is seen that female jumpers generally maintain their hop-jump balance like male jumpers, that is, they use the balance dominant technique.

Table 6. 1992 USA Track and Field Olympic Team Trials Analysis of Phase Rates and Distances of Men's Triple Jump Finalists (Liu and Yu, 2012).

\begin{tabular}{|c|c|c|c|c|c|c|}
\hline $\mathrm{N}$ & Hop (m) & Step (m) & Jump (m) & Hop (\%) & Step (\%) & Jump (\%) \\
\hline \multirow{13}{*}{13} & 6.51 & 5.85 & 5.52 & 36 & 33 & 31 \\
\hline & 5.77 & 5.42 & 6.86 & 32 & 30 & 38 \\
\hline & 6.04 & 5.34 & 5.87 & 35 & 31 & 34 \\
\hline & 6.28 & 5.65 & 5.24 & 37 & 33 & 30 \\
\hline & 6.17 & 5.22 & 5.73 & 36 & 30 & 34 \\
\hline & 6.62 & 5.87 & 5.92 & 38 & 28 & 34 \\
\hline & 6.12 & 5.67 & 5.60 & 36 & 31 & 33 \\
\hline & 5.69 & 5.10 & 5.93 & 34 & 31 & 35 \\
\hline & 5.78 & 5.02 & 5.85 & 35 & 30 & 35 \\
\hline & 5.69 & 5.20 & 5.71 & 34 & 31 & 35 \\
\hline & 6.01 & 5.00 & 5.51 & 36 & 30 & 34 \\
\hline & 5.72 & 4.84 & 5.85 & 35 & 29 & 36 \\
\hline & 5.69 & 4.62 & 5.14 & 37 & 30 & 33 \\
\hline Mean & 6.00 & 5.29 & 5.74 & 35 & 30 & 34 \\
\hline
\end{tabular}

When Table 6 is examined, it is seen that male jumpers generally maintain their hop-jump balance in average phase ratios and distances, that is, they use the balance dominant technique.

\section{DISCUSSION AND RESULT}

In the research, the techniques used by the jumpers dominantly on the basis of ratio and distance in the triple jump hop-step-jump phases, and the biomechanical analysis of the complex motion cycle in 
the triple jump with the reverse dynamic simulation method were examined. In the review, it was noted that the resources related to the subject in the literature are few and insufficient for the meta-analysis examination methods designed to be done.

Applications for triple jump motion analysis are very few. For this reason, the kinematic models revealed, knowing the external and internal loads that the athlete is exposed to during jump, measuring the pressure and impact occurring at the contact/fall moment between the ground and the foot, and inverse dynamic analyzes in order to comment on the interaction of muscle forces are important sources.

Thanks to the mentioned mechanisms, the information received will be a guide for the individual jumpers in the next training and competitions, and in this regard, it creates areas where coaches can criticize and predict changes in training planning.

As it should be in all branches of athletics, continuous training and competition analysis in triple jump will increase the feedback-correction interaction between the athlete-coach quantitatively and qualitatively. In this branch, where even a very small $(\mathrm{cm})$ progress on the basis of distance is seen as important (success rank and progress in degrees), being able to carry out regular movement analysis will create an important addition to the training, physical, psychological and physiological factors of success, and will allow professional correction and progress in the technical dimension.

When the ratio and distance outputs in the hop-step-jump phases were examined, it was seen that Enas Gharieb used the jump dominant (De Silva) technique in his trials $(4.17 \mathrm{~m}-3.69 \mathrm{~m}-4.69 \mathrm{~m})$ (Eissa, 2014). When the Berlin 2009 triple jump final was examined, it was seen that both female jumpers (37\%-29\%-34\%) and male jumpers (37\%-30\%-33\%) used the hop dominant technique (Hommel, 2009). When the Daegu 2011 triple jump final was examined, it was seen that both female jumpers (36\%-29\%$35 \%$ ) and male jumpers (36\%-30\%-34\%) used balance dominant technique (Woo and Kim, 2011). It was observed that male jumpers (35\%-30\%-34\%) used balance dominant technique in the 1992 USA athletics Olympic team trials (Liu and Yu, 2012).

However, Liu and $\mathrm{Yu}$ (2012), in their study to examine the effect of phase ratio on triple jump performance (mentioned above), argued that balance dominant technique was not an optimal technique for triple jump in terms of performance indicators (horizontal and vertical take-off speeds in phases, speed losses, etc.). With this claim, they rejected the study of Jeremin (1970), who advocates the relationship of the balanced technique with the optimum phase ratio (37\%-28\%-36\%) and stated that it is inconsistent. In studies conducted on biomechanics-based studies, it has been stated that the speed conversion coefficient has a primary effect on the optimum phase. The speed conversion coefficient is decisive in the optimum ratio-performance-distance balance, since it also affects the efficiency of vertical acceleration in terms of horizontal speed losses in all phases of the triple jump ( $\mathrm{Yu}, 1999)$.

Knowing the physical, anthropometric, and technical basis that affect the biomechanical factor of the triple jump and have a contact on the specified parameters, revealing the relationship between them, if any, and supporting them by many studies will be important in terms of selection, orientation and performance improvement of the jumpers.

As a result, considering the degrees that emerged, according to the results of the competition examined, it was seen that the quantitative success was higher in men in the phases where the balance dominant technique was used, while it was seen that close results were obtained in both the hop dominant and balance dominant techniques in women. In the important national and international competitions, it has been observed that while the jumpers used the jump dominant technique widely before, this situation has been replaced by more balance and hop dominant techniques recently. 


\section{REFERENCES}

Allen, S. J. (2009). Optimization and Performance in the Triple Jump Using Computer Simulation. PhD Thesis: Loughborough University, Loughborough, UK.

Bayraktar, I., \& Çilli, M. (2017). Uzun ve Üç Adım Atlama Branşlarında Biyomekanik Analizler. Nobel Akademik Yayıncılık, 1. Basım, Ankara.

Blajer, W., Czaplicki, A., Dziewiecki, K., \& Mazur, Z. (2010). Influence of Selected Modeling and Computational Issues on Muscle Force Estimates. Multibody System Dynamics, 24, 473-492.

Čoh, M., Matjačić, Z., Peharec, S., Bačić, P., Rausavjević, N., \& Maćkala, K. (2015). Kinematic, Dynamic and EMG Analysis of Drop Jumps in Female Elite Triple Jump Athletes. Coll Antropol., 39 (Suppl 1), 159-66.

Eissa, A. (2014). Biomechanical Evaluation of the Phases of the Triple Jump Take-Off in a Top Female Athlete. Journal of Human Kinetics, 40, 29-35.

Erdemir, A., McLean, S., Herzog, W., \& Van Den Bogert, A. (2007). Model-Based Estimation of Muscle Forces Exerted During Movements. Clinical Biomechanics, 22, 131-154.

Garner, B.A., \& Pandy, M.G. (2000). The Obstacle-Set Method for Representing Muscle Paths in Musculoskeletal Models. Computer Methods in Biomechanics and Biomedical Engineering, 3, 1-30.

Hay, J. G. (1992). The Biomechanics of the Triple Jump: A Review. Journal of Sports Sciences, 10, 343-378.

Hay, J. G. (1999). Effort Distribution and Performance of Olympic Triple Jumpers. Journal of Applied Biomechanics, 15, 36-51.

Hommel, H. (2009). Long Jump (Final Report) - Scientific Research Project Biomechanical Analyses at the IAAF World CH in Athletics - Berlin. Darmstadt; 2009. https://www.iaaf.org/development/research.

Jeremin, J. (1970). Experimente im Dreisprung [Experiment in the triple jump]. Die Lehre der Leichtathletik, 26, 737-738.

Koh, T.J., \& Hay, J.G. (1990). Landing Leg Motion and Performance in the Horizontal Jumps II: The Triple Jump. International Journal of Sport Biomechanics, 6, 361-373.

Liu, H., \& Yu, B. (2012). Effects of Phase Ratio and Velocity Conversion Coefficient on The Performance of the Triple Jump. Journal of Sports Sciences, 30(14), 1529-1536.

Miladinov, O., \& Bonov, P. (2004). Individual Approach in Improving the Technique of Triple Jump for Women. New Studies in Athletics, 19(4), 27-36.

Perttunen, J., Kyrolainen, H., Komi, P.V., \& Heinonen, A. (2000). Biomechanical Loading in the Triple Jump. Journal of Sports Sciences, 18, 363-370.

Robertson, D.G.E., Caldwell, G.E., Hamill, J., Kamen, G., \& Whittlesey, S. N. (2004). Research Methods in Biomechanics. Human Kinetics, Champaign, IL.

Seireg, A., \& Arvikar, R. (1989). Biomechanical Analysis of the Musculoskeletal Structure for Medicine and Sports. Hemisphere Publishing Corporation, New York, USA.

Winter, D. A. (2005). Biomechanics and Motor Control of Human Movement. 3th Edition. Wiley, New York, USA.

Woo, S. Y., \& Kim, Y. W. (2011). Triple Jump Biomechanics Research Report from the IAAF World Championships Daegu-2011. http://www.jaaf.or.jp/t-f/pdf/Daegu2011.pdf.

Yu, B. (1999). Horizontal-to-Vertical Velocity Conversion in the Triple Jump. Journal of Sports Sciences, 17(3), 221-229.

Yu, B., \& Hay, J. G. (1996). Optimum Phase Ratio in the Triple Jump. Journal of Biomechanics, 29, 1283-1289.

Zajac, F.E., \& Winters, J.M. (1990). Modeling Musculoskeletal Movement Systems: Joint and Body Segmental Dynamics, Musculoskeletal Actuation, and Neuromuscular Control. In: Winters, J.M., Woo S.L.Y. (eds.) Multiple Muscle Systems: Biomechanics and Movement Organizations. Springer, Berlin, 121-148. 